\title{
Biodigestores e Biogás na Suinocultura Catarinense
}

\author{
Biodigesters and Biogás in Catarinense Suinoculture
}

\author{
Francisco Gelinski Neto \\ fgelneto@gmail.com \\ Universidade Federal de Santa Catarina (UFSC) \\ Eduardo Gelinski Junior \\ gelinskieduardo@gmail.com \\ Universidade Federal de Santa Catarina (UFSC) \\ Filipe Guesser \\ lipe.guesser@hotmail.com \\ Universidade Federal de Santa Catarina (UFSC)
}

Resumo: A suinocultura é importante na economia brasileira e catarinense. O Brasil é quarto exportador de carne suína. Em Santa Catarina o produto é o segundo em Valor Bruto de Produção. Porém, a suinocultura é uma atividade visada por problemas ambientais. A preocupação neste trabalho são as emissões de metano geradas pelos efluentes da atividade. Nesse sentido, o objetivo é verificar a utilização da tecnologia de coleta e queima de biogás nas experiências feitas em três microrregiões de Santa Catarina (Joaçaba, Concórdia e Xanxerê) avaliando a evolução e dificuldades e o grau de utilização de biodigestores do modelo Canadense de fluxo contínuo. As entrevistas com técnicos e outros permitiram verificar a dificuldade de manutenção dos biodigestores, o que motivou o seu abandono por muitos produtores. Não há expectativa de ampliação de uso no curto prazo se não houver solução tecnológica e financeira para estímulo aos produtores.

Palavras-chave: Suinocultura; Biogás; Biodigestores

\begin{abstract}
Swine farming is important in the Brazilian and Santa Catarina economy. Brazil is the fourth exporter of pork. In Santa Catarina, the product is the second in Gross Production Value. However, swine farming is an activity targeted by environmental problems. The concern in this work is the methane emissions generated by the activity effluents. In this sense, the objective is to verify the use of biogas burning and collection technology in the experiments carried out in three microregions of Santa Catarina (Joaçaba, Concórdia and Xanxerê) evaluating the evolution and the difficulties and the degree of use of biodigesters of the Canadian flow model continuous. The interviews with technicians and others allowed to verify the difficulty of maintaining the biodigesters, which motivated their abandonment by many producers. There is no expectation of expanding use in the short term if there is no technological and financial solution to stimulate producers.
\end{abstract}

Keywords: Poultry; Biogas; Biodigesters 


\section{INTRODUÇÃO}

O Brasil é um dos principais produtores e exportadores de carne suína do mundo. A suinocultura brasileira contribui com $1,74 \%$ do total das receitas de exportações do agronegócio em 2016 que atingiram US\$ 84,9 bilhões (COMEX DO BRASIL, 2017). Em 2016 foram exportados US\$ 1,483 bilhão de dólares de carne suína. O Brasil é $4^{\circ}$ colocado em termos de produção e de exportação de carne suína no mundo. Porém, a produção brasileira poderia ser bem maior se comparada aos demais países com área geográfica semelhante. Por exemplo, os chineses produzem 51,8 milhões de toneladas, a União Européia 23,3, os EUA 11,3 e o Brasil apenas 3,7 milhões de toneladas (GIEHL, 2016).

No Brasil, Santa Catarina é o $1^{\circ}$ colocado na produção nacional de suínos, com aproximadamente 934 mil toneladas. Nesse estado a atividade tem a segunda posição em termos de valor bruto da produção (VBP), aproximadamente 3,96 milhões de reais, e só perde para a produção de carne de aves, com 7,8 milhões de reais. (TORESAN, 2016). São aproximadamente 8 mil produtores suínos em Santa Catarina ${ }^{1}$ (ACCS, 2011).

Porém, quando a preocupação é o meio ambiente a atividade é visada pelo grande volume de efluentes (sólidos, líquidos e gasosos) gerados. A produção de resíduos/estercos atinge tal volume que a legislação ambiental $^{2}$ restringiu a atividade dos produtores à disponibilidade de área para distribuir os resíduos e, com isso, minorar o risco de poluição.

Pelo menos desde o início dos anos 90, em Santa Catarina havia a preocupação com os dejetos oriundos da criação de suínos. Naquele momento o problema estava relacionado, sobretudo, à poluição causada por coliformes fecais. Iniciava-se então uma grande movimentação para a busca de financiamentos e apoio para a construção de esterqueiras, lagoas de decantação e outros tratamentos para reduzir o impacto da atividade que era crescente no Estado. Por exemplo, no II Seminário de Administração Rural ocorrido na Cidade de Concórdia em dezembro de 1992 foi amplamente discutido o problema ambiental provocado pela suinocultura ${ }^{3}$. Isto foi emblemático por que Concórdia é um dos principais

\footnotetext{
1 A forte concentração da suinocultura nos últimos anos resultou na formação de grandes conglomerados agroindustriais com condições de disputar o mercado nacional e internacional. Na produção dos suínos ainda há presença significativa de pequenos agricultores familiares que se relacionam com as agroindústrias processadoras de carne no "sistema integrado de produção", os independentes são minoria (SANTOS FILHO et alii, 2015, p.7).

${ }^{2}$ Conforme a instrução Normativa $n^{\circ} 1 / 2009$ da então FATMA - Fundação do Meio Ambiente de Santa Catarina - que a partir de 2017 se converte no Instituto do Meio Ambiente, o IMA.

${ }^{3}$ Naquele momento o maior problema era a poluição por coliformes fecais que afetavam os rios no estado.
} 
polos de criação de suínos em Santa Catarina, berço da EMBRAPA Suínos e Aves e da SADIA. ${ }^{4}$

TESTA et alii (1996) já naquela época preconizavam que o ideal seria ter, no máximo, 25 matrizes por propriedade (no ciclo completo) visando a sustentabilidade econômica e ambiental. Dessa forma estaria assegurada a eficiente distribuição e ou tratamento de esterco sem gerar poluição. Obviamente, dadas as atuais escalas ${ }^{5}$, essa situação não existe mais. A pressão de custos e preços tornou a pequena escala impossível, além de levar os produtores a se especializarem em uma etapa do ciclo $^{6}$.

Em 1995, embora o rebanho catarinense estivesse em torno de 4,4 milhões de cabeças, já era preocupante o problema dos dejetos (MACHADO, 1999). Com o atual tamanho de rebanho os problemas com efluentes são maximizados, pois, foram produzidas 6,8 milhões de cabeças em 2015 (IBGE, 2016). Estes animais geram aproximadamente $47.500 \mathrm{~m}^{3}$ de dejetos (efluentes $\left.{ }^{7}\right)$ diariamente.

Dos efluentes, se corretamente tratados, pode-se obter biofertilizante e biogás ${ }^{8}$. O biogás é a fermentação anaeróbica dos dejetos/efluentes e produzirá, entre outros, o metano. Para se evitar a liberação do metano na atmosfera se podem utilizar biodigestores que permitem a coleta e queima do biogás. O metano e o dióxido de carbono presentes no biogás são responsáveis pelo efeito estufa no globo terrestre (ABREU, AVELINO, 2012, apud TORRES e SILVA, 2015). O uso de biodigestores e os sistemas integrados de tratamento são mais eficientes na remoção da carga poluente comparativamente à utilização de simples esterqueiras, mas apresentam maiores custos o que torna restritivo para utilização de muitos produtores (MAIA et alii, 2015).

Paralelamente à problemática ambiental há que se considerar os ciclos econômicos da atividade de criação de suínos. É uma atividade que sempre tem sofrido pressão de custos a ponto de culminar com gigantescas escalas de operação e exclusão de produtores em razão de

\footnotetext{
${ }^{4}$ Empresa que desde 2013, junto com a Perdigão, compõe a BRF (Brasil Foods). O processo de fusão se iniciou em 2009.

${ }^{5}$ De mais de 50000 produtores no estado atualmente produzem suínos em Santa Catarina cerca de 8.000 produtores. Isto implicou em elevação do número de animais por propriedade (ACCS, 2011).

${ }^{6}$ Os produtores são especializados em i) matrizeiros (mantém as fêmeas que reproduzem os fillhotes até a desmama); ii) os que fazem a recria ou crechário (cuidam dos filhotes desde a desmama até $22 \mathrm{~kg}$ ) e; iii) os terminadores (fazem a engorda dos animais e envio ao frigorífico). Podem ocorrer raramente os produtores de ciclo completo. A EMBRAPA classifica em Unidade de Ciclo Completo - UCC, Unidade de Produção de Leitões - UPL, e Unidade de Crescimento e Terminação - UCT.

${ }^{7}$ A composição dos efluentes/dejetos contém urina e fezes dos animais, água e restos de ração com elevado potencial poluidor. Nesse material existem altas concentrações de compostos nitrogenados e fosfatados, coliformes fecais e sólidos suspensos que podem atingir rios, lençóis subterrâneos e lagos se não tratados (DIESEL et alii, 2002).

${ }^{8}$ A composição do biogás em maior percentual é de metano (entre 50 a $\left.70 \%\right)$ e dióxido de carbono (30\%) OLIVEIRA et al (2006). O metano é 21 vezes mais poluente que o dióxido de carbono.
} 
problemas ligados normalmente à elevação de custos de matérias primas e/ou de mercado com preços deprimidos (GRIEBELER, 2002; TESTA et alii, 1996). Por exemplo, Rodrigues et alii (2013) verificaram que houve desvantagem econômica dos produtores de suínos de Santa Catariana na maioria dos meses do período compreendido entre janeiro de 2000 e setembro de 2012 quando a relação de trocas foi desfavorável aos produtores. Nesses casos, o investimento em sistema de biodigestão pode tornar-se dificultoso pois, a geração de caixa será insuficiente para arcar com esse tipo de investimento colocando em risco a sustentabilidade econômica do produtor.

Porém, em um momento em que há uma preocupação crescente quanto à preservação do meio ambiente e à sustentabilidade, é natural que cresçam as exigências legais sobre a atividade. O mundo está preocupado, entre outros aspectos, com questões relacionadas ao bem-estar animal e à problemática dos gases do efeito estufa (GEE). Inclusive o Programa brasileiro agricultura baixo carbono $(\mathrm{ABC})$ é um esforço no sentido de estimular os produtores a adotarem mecanismos redutores dos GEE e de conservação de recursos naturais conforme compromisso Brasileiro na $15^{\text {a }}$. Conferência das Partes (COP-15) 9 .

Nesse contexto, este trabalho pretende elucidar algumas questões: Como está atualmente a utilização de biodigestores nas principais regiões produtoras de suínos em Santa Catarina, a saber, as microrregiões de Concórdia, Joaçaba, Xanxerê e as perspectivas para esta prática.

O objetivo geral é levantar o grau de utilização do tratamento de dejetos de suínos por meio do uso de biodigestores em 3 Microrregiões de Santa Catarina. Os objetivos específicos são: i) descrever/levantar a importância da eliminação do metano; ii) verificar a existência de estímulos ou incentivos para instalação de sistema de biodigestão; iv) verificar exemplos de programas de biodigestores em Santa Catarina; e v) relatar as dificuldades na implantação e manutenção de um sistema de biogás.

Trata-se de uma pesquisa descritiva que utiliza dados primários e secundários ${ }^{10}$. É um estudo com escopo na economia da produção agrícola e da economia ambiental. A área geográfica de estudo abrange as Microrregiões de Concórdia, Joaçaba, Xanxerê. Tais microrregiões estão classificadas como $1^{\circ}, 2^{\circ}$ e $5^{\circ}$ produtores de suínos em termos de volume no Estado de acordo com Giehl (2016). Os dados primários foram obtidos com entrevistas

\footnotetext{
${ }^{9}$ Realizada em Copenhague, Dinamarca em dezembro de 2009. O país já dispunha de uma Política Nacional sobre mudanças climáticas naquele momento. É a Lei 12.187 de 2009 que busca garantir que o desenvolvimento econômico e social contribua para a proteção do sistema climático global. O Decreto n.7.390/2010 a regulamenta estabelecendo os limites de emissão gases de efeito estufa pelo país para o ano de 2020.

${ }^{10}$ Os dados da pesquisa foram obtidos em 2016 e início de 2017.
} 
junto a técnicos de cooperativas e Empresas públicas que trabalham na região ${ }^{11}$, empresas privadas (Granja São Roque e Granja Comelli). Os dados secundários são de relatórios técnicos das agroindústrias, Epagri, Cidasc, dissertações e outras fontes bibliográficas de periódicos indexados.

\section{A SUINOCULTURA E A POLUiÇÃo}

Inicia-se esta seção verificando-se os tipos de poluição e o que define a lei. As principais formas de poluição são: i) Poluição hídrica; ii) Poluição atmosférica ${ }^{12}$; iii) Poluição do solo; iv) Poluição sonora; v) Poluição visual; vi) Poluição radioativa (SANTOS et alii, 2002 apud GUESSER, 2016). Segundo o artigo $3^{\text {a }}$ da Lei de $n^{\circ} 6.938 / 81$ que trata da Política Nacional do Meio Ambiente,

(...) poluição é a degradação da qualidade ambiental resultante de atividade que direta ou indiretamente: prejudiquem a saúde, a segurança e o bem-estar da população; criem condições adversas às atividades sociais e econômicas; afetem desfavoravelmente a biota; afetem as condições estéticas ou sanitárias do meio ambiente; lancem matérias ou energia em desacordo com os padrões ambientais estabelecidos (BRASIL 1981 apud GUESSER, 2016, p.30).

A poluição ambiental causada por dejetos oriundos da suinocultura abrange elevado número de contaminantes que causam forte degradação do ar, do solo e principalmente dos recursos hídricos (águas superficiais e subterrâneas). O lançamento direto de estercos em cursos de água é a principal causa de poluição (NOLASCO et alii, 2005). O problema ambiental da suinocultura está no aumento do número de animais por metro quadrado na busca por economia de escala. Ao se aumentar o número de animais a consequência natural é o aumento do volume de dejetos. Caso não sejam tratados comprometerão o ambiente (WEYDMANN, 2014).

Nesse sentido, Valente et alii (2013, apud GUESSER, 2016) concluíram que na região Sul do Brasil a criação de suínos é altamente tecnificada em sistemas de confinamento, o que propicia grande concentração de animais por metro quadrado gerando um grande volume de resíduos orgânicos, principalmente na forma líquida. Isso exigiria cuidados especiais com relação ao seu manejo, armazenamento e distribuição.

\footnotetext{
${ }^{11}$ A Cooperdia em Concórdia, a Epagri, a Embrapa e a Fatma.

${ }^{12}$ A poluição do ar pode ser definida como a modificação da sua composição química, seja pelo desequilíbrio dos seus elementos constitutivos, seja pela presença de elemento químico estranho que venha causar dano ao equilíbrio do meio ambiente e, consequentemente, à saúde dos seres vivos.
} 
Maiores exigências da legislação ambiental bem como pressões do mercado consumidor têm levado as cadeias agroindustriais a ações pró-sustentabilidade ambiental e maior transparência em sua atuação relativamente aos recursos ambientais. O setor suinícola tem sido incentivado a reciclar os seus resíduos no sentido de obter maiores rendimentos e gerar menos resíduos a serem tratados (VALENTE et alii, 2013). Weydmann (2014), comparando a legislação brasileira à de países produtores importantes - Japão, Alemanha e Holanda - com escassez de área para utilizar os dejetos como fertilizante, verificou que estes têm evitado a expansão do setor por meio de proibições ou de legislação ambiental mais severa.

\subsection{A LEI E A NORMA PARA O LICENCIAMENTO AMBIENTAL DA ATIVIDADE ${ }^{13}$}

Esta seção trata das leis e da instrução normativa que regem o meio ambiente e a suinocultura em Santa Catarina e os tipos de licenças necessárias pelos produtores. Outorgada em 13 de abril de 2009, a lei estadual $n^{\circ} 14.675 / 09$ foi a responsável por instituir o código estadual do meio ambiente. Para a execução da atividade os suinocultores devem seguir uma série de normas, estas definidas pela Fundação do Meio Ambiente (FATMA), atual IMA, com base no código estadual. A instrução normativa $n^{\circ} 11$ que define a documentação necessária para o licenciamento e estabelece critérios para apresentação dos planos, programas e projetos ambientais para implantação de atividades relacionadas à suinocultura de pequeno, médio e grande porte, incluindo tratamento de resíduos líquidos, tratamento e disposição de resíduos sólidos, emissões atmosféricas, ruídos e outros passivos ambientais (FATMA, 2014, p.1).

Segundo Palhares (2008), as licenças ambientais requeridas pela legislação brasileira para produção animal são: i) Licença prévia (LP) requerida na fase de avaliação da viabilidade do empreendimento; ii) Licença de instalação (LI); iii) Licença de operação (LO) - esta tem prazo máximo de dez anos. A licença de operação: i) Contém as medidas de controle ambiental (padrões ambientais) que servirão de limite para o funcionamento do empreendimento ou atividade; ii) Especifica as condicionantes determinadas para a operação do empreendimento, cujo cumprimento é obrigatório sob pena de suspensão ou cancelamento da operação. Estas licenças visam minorar o problema da poluição causada pela atividade em questão.

\footnotetext{
${ }^{13}$ É um procedimento administrativo pelo qual o órgão ambiental competente licencia a atividade em tela. A resolução do CONSELHO NACIONAL DO MEIO AMBIENTE (CONAMA) $n^{\circ} .237 / 97$ estabelece o alcance e exigências para o licenciamento.
} 


\subsection{O MANEJO DOS DEJETOS NA SUINOCULTURA E O BIOGÁS}

O tratamento de dejetos na agricultura em especial da suinocultura pode ser feito por meio de sistemas mais simples. Neste caso se podem obter apenas adubos. São eles: i) Esterqueiras; ii) Compostagem; iii) Cama biológica; iv) Lagoas de decantação. Outros tratamentos envolvem o uso de biodigestores e até o sistema denominado de integrado.

Considerando que os dejetos são compostos por sólidos, líquidos e gás, as formas de tratar o problema diferem conforme os investimentos necessários e os resultados visados. Pode-se priorizar, no tratamento de dejetos, apenas a geração do adubo ou ainda adubo e biogás ou, além destes, pode-se obter por meio de sistema integrado o adubo, biogás e o cultivo de peixes (SAVIOTTI, et alii, 2016).

Para obtenção de biogás e biofertilizante pode ser utilizado o biodigestor que permite a fermentação aneróbica dos efluentes e a geração de biogás. Os biodigestores são capazes de gerar energia por meio da coleta e queima dos gases oriundos do processo de fermentação aneróbica e viabilizam o aproveitamento do biofertilizante reduzindo os resíduos poluentes dos dejetos animais. Outra vantagem é a redução do mau cheiro ao remover os gases, além de reduzir a carga orgânica e concentrar os nutrientes por unidade de volume valorizando o uso do biofertilizante em áreas de lavouras e pastagens (HENN, 2005; OLIVEIRA, 2004 apud Maia et alii 2015).

Outra forma de tratamento de dejetos é o sistema integrado que, conforme o próprio nome diz, integra biodigestor, tanque de sedimentação, lagoa de aguapés e tanque de piscicultura (figura 1) Os sistemas integrados permitiriam remover praticamente toda a carga poluente ao utilizar lagoa de aguapés e tanque de piscicultura (MAIA et alii 2015, p.226).

Figura 1 - Esquema de um sistema integrado com biodigestor

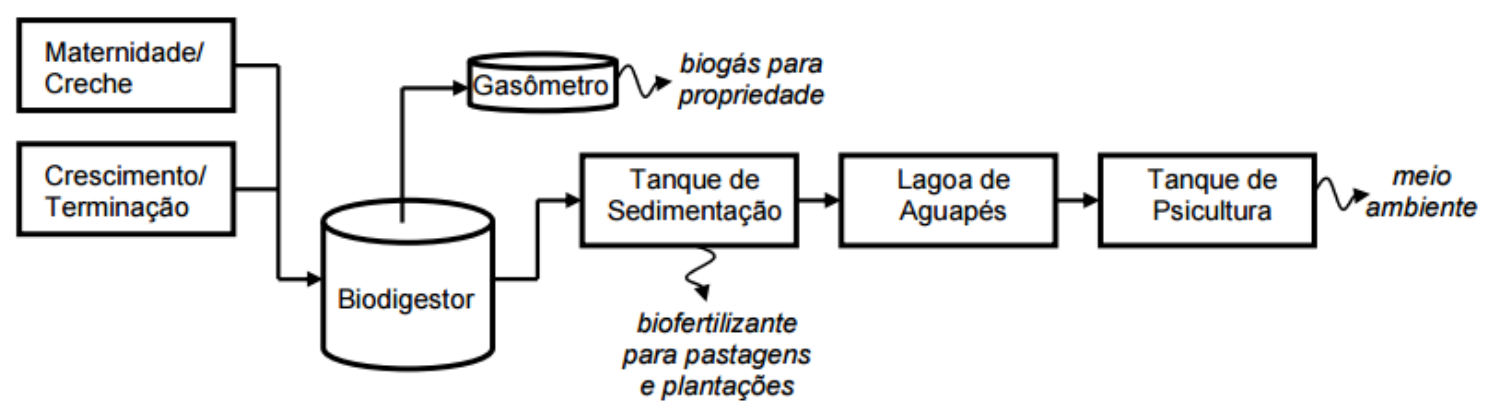

Fonte: MAIA et alii 2015, p. 226. 
Uma das principais preocupações ambientais, e que está fortemente ligada à produção de suínos, é a emissão de gases causadores do efeito estufa (GEE), em especial o metano que absorve muito a radiação solar na superfície da terra e aumenta o efeito estufa. A concentração global deste gás vem aumentando em média a uma taxa de $1 \%$ ao ano, sendo que $80 \%$ deste gás é oriundo da decomposição de matéria orgânica. "O grande desafio das regiões com alta concentração de animais é a exigência da sustentabilidade ambiental, energética e a redução da emissão dos GEE (OLIVEIRA et al, 2006).

A utilização de biodigestores ou de sistema integrado pode minorar o impacto ambiental gerando benefícios ambientais e econômicos aos produtores se resolvido o problema de manutenção. Nosso levantamento junto aos produtores e técnicos verificou o baixíssimo grau de utilização e mesmo o abandono do sistema. Por exemplo, Kruger (2016) verificou que apenas 5\% dos produtores de uma amostra de 163 gestores rurais do Oeste de SC possuem biodigestores para o tratamento dos resíduos gerados pela produção suinícola. "No Brasil, há aproximadamente 2500 biodigestores instalados. É um baixo número comparado às 700 mil propriedades que produzem suínos no país. Destes já instalados, apenas 5\% são destinados a produção de energia” (BIONDO, 2015, p.1).

Há mais de trinta anos (décadas 70 e 80) o interesse pelo uso de biodigestores e o biogás esbarrou no custo dos equipamentos e menor conhecimento tecnológico e inexistência de materiais e complementos acessíveis. Atualmente a disponibilidade de novos materiais mais acessíveis e o alto custo da energia, aliada a novas tecnologias possibilitaria maior alcance e disseminação do uso dos biodigestores com finalidade energética e biofertilização. Embora a ênfase nesta seção seja a obtenção de adubos e biogás para utilização econômica as decisões sobre as várias formas de tratamento dos dejetos podem envolver o interesse de diversos stakeholders (produtores, agentes reguladores, governos e consumidores). Estes podem estar interessados na redução de emissões de gases de efeito estufa que contribuem para o aquecimento global. (OLIVEIRA; HIGARASHI, 2006).

\section{SUINOCULTURA DE BAIXO CARBONO E RENDIMENTOS DO BIOGÁS}

Há urgência em ações para reverter o quadro antagônico em parte da população com relação à produção animal em razão da produção de metano nas atividades pecuárias. Neste sentido, Gerber et alii (2013, apud EMBRAPA, 2016) destacam justamente a atuação de movimentos populares para redução e exclusão do consumo de carne por considerarem a produção animal como uma das principais emissoras de GEE. "A pecuária é responsável por grande parte dessa emissão de GEE, sendo que $9 \%$ é atribuído à produção de suínos. Desse 
montante de $9 \%, 16 \%$ é responsabilizado pela produção de metano devido ao manejo inadequado de dejetos" (GERBER et al, 2013, apud SAVIOTTI et alii, 2016, p.41).

A suinocultura, como outras atividades da agricultura brasileira, está enquadrada na necessidade de contribuir para o esforço do país em cumprir o compromisso voluntário de redução de emissão de gases de efeito estufa ${ }^{14}$ que foi firmado durante a $15^{\text {a }}$ Conferência das Partes (COP-15).

Na COP-15 o Brasil comprometeu-se a reduzir de 36,1\% a 38,9\% das emissões de GEE projetadas para 2020. Para isto o governo elaborou o Plano Setorial de Mitigação e de Adaptação às Mudanças Climáticas para a Consolidação de uma Economia de Baixa Emissão de Carbono na Agricultura ${ }^{15}$, também denominado Plano ABC - Agricultura de Baixa Emissão de Carbono (BRASIL, s/d). O Plano ABC tem por finalidade a organização e o planejamento das ações a serem realizadas para a adoção das tecnologias de produção sustentáveis $^{16}$. O setor agropecuário respondeu por $37 \%$ das emissões totais em 2012, figurando, junto com o setor de energia, como o maior emissor setorial (Brasil, 2014, apud GURGEL et alii, 2016).

Se por um lado a agricultura é emissora de carbono em razão da produção de alimentos na forma intensiva para suprir a oferta necessária às populações crescentes e a excessiva dependência da queima de combustíveis fósseis ao longo das cadeias agroindustriais, por outro ela receberá os impactos do aquecimento global em razão das intempéries que se abaterão sobre os campos de produção. As intempéries podem ser inundações, vendavais, temperaturas extremas ou outro que afetarão a produção. Segundo o Ministério da Agricultura Pecuária e Abastecimento (MAPA, 2011), a ocorrência da mudança do clima pode afetar a produção agropecuária e trazer consequências negativas e imprevisíveis para esse setor, por que deverá ocorrer: i) Aumento na concentração de CO2; ii)

\footnotetext{
${ }^{14} \mathrm{O}$ fenômeno conhecido como "efeito estufa" ocorre quando a radiação solar, que chega ao Planeta na forma de ondas curtas, passa pela atmosfera, aquece a superfície terrestre, refletindo de volta para a atmosfera parte dessa radiação na forma de calor, em comprimentos de onda infravermelha. Na presença de alguns elementos gasosos da atmosfera a reflexão é bloqueada e, dessa forma, intensificando a retenção de calor nas camadas mais baixas da atmosfera. Esse fenômeno é natural e importante para a manutenção da temperatura, considerada dentro dos limites aceitáveis à vida no Planeta (MAPA, 2011, p.9). O problema é a retenção excessiva na presença de gases prejudiciais elevando sobremaneira a temperatura da terra. As fontes de emissão de GEE são: queima de combustíveis fósseis, desmatamento, drenagem de pântanos, fertilizações nitrogenadas ineficientes, queimadas, preparo intensivo do solo entre outros. As atividades agrícolas geram emissões diretas e indiretas de GEE por diversos processos, os mais conhecidos são a fermentação entérica nos herbívoros ruminantes $(\mathrm{CH} 4)$, produção de dejetos de animais ( $\mathrm{CH} 4$ e N2O), preparo convencional do solo (CO2), cultivo de arroz inundado (CH4), queima de resíduos agrícolas (CO2, CH4, N2O), entre outros (MAPA, 2011, p.30).

15 "A agricultura de baixa emissão de carbono é aquela capaz de reduzir as emissões de gases de efeito estufa (GEEs) provenientes da atividade agropecuária através de práticas agrícolas e tecnologias capazes de diminuir a intensidade de emissões" (GURGEL et alii 2016, p.343).

${ }^{16} \mathrm{O}$ Plano ABC é composto por sete programas. O programa referente aos dejetos é sexto: denominado de Tratamento de Dejetos Animais.
} 
Aumento da temperatura do ar e do solo; iii) Aumento de secas e chuvas torrenciais que trarão diversos impactos sobre a produtividade e sobrevivência de animais e plantas (GUESSER, 2016). A agricultura garante a sobrevivência da espécie humana e não pode ser considerada a maior responsável pelo aquecimento global.

Em 2016 o Ministério da Agricultura, Pecuária e Abastecimento, desenvolveu acordo de cooperação com o Instituto Interamericano de Cooperação para a Agricultura (IICA). Esse acordo visava operacionalizar o projeto Suinocultura de Baixa Emissão de Carbono no escopo do Plano ABC. Foram contratados consultores para divulgar modelos e maneiras de economizar carbono na suinocultura. Entre outras ações, os consultores realizaram Fóruns de Suinocultura de Baixa Emissão de Carbono em várias regiões do país ${ }^{17}$ (MAPA..., 2016).

Empresas agroindustriais e governamentais estimularam os agricultores a utilizarem biodigestores, porém, conforme se verá adiante neste trabalho, após euforia inicial a utilização destes equipamentos para eliminação de gases deixou de ser interessante, pois, o porte dos produtores e a tecnologia empregada interferem na continuidade do uso. Parece que o modelo atual, o biodigestor modelo canadense apresentou problemas operacionais a ponto de ter ocorrido abandono em muitas propriedades como se verá adiante neste trabalho. Outro aspecto é o estímulo financeiro. Por exemplo, Wander et alii (2016) verificaram que houve menor tomada de recursos para tratamento de dejetos nas safras 2011/12 e 2012/13. De 9,9 milhões de reais e 22 contratos, o valor utilizado do Plano ABC/Plano Safra caiu para 7,3 milhões de reais, indicando retrocesso na área de tratamento de dejetos na agricultura.

\section{BIOGÁS - ALGUMAS ESTIMATIVAS}

O biogás é uma mistura de gases obtidos pela fermentação por bactérias anaeróbicas (ausência de oxigênio) de resíduos orgânicos de origem animal ou vegetal. Na sua composição estão presentes entre outros o metano e o gás sulfídrico. A combustão do biogás gerado no biodigestor evita a liberação de metano ao ambiente ${ }^{18}$. Além disso, “(...) o efluente ao passar pelo biodigestor tem melhorada as condições do material residual para finalidade

\footnotetext{
${ }^{17} \mathrm{O}$ objetivo central foi mostrar as vantagens e benefícios do tratamento e utilização dos resíduos animais principalmente na obtenção de energia, biofertilizantes e renda, além de mitigar os impactos ambientais ao utilizar os gases do efeito estufa de maneira positiva na geração de energia. O biofertilizante gera ganho ao propiciar menor aquisição de adubos químicos. Em Santa Catarina duas cidades receberam o fórum: Concórdia e Florianópolis. Diversas outras cidades do Paraná, Minas Gerais e Mato Grosso também. Teriam sido alcançados 1.300 participantes que a partir das palestras e casos poderão repensar o modelo de produção nas fazendas (MAPA..., 2016).

${ }^{18}$ Além do metano e dióxido de carbono são encontrados em menor proporção no biogás o gás sulfídrico e o óxido nitroso.
} 
agrícola, pois, aumenta a solubilidade de alguns nutrientes no biofertilizante" (AMARAL et alli, 2006, p.41).

Em termos de geração de energia o biogás propicia os seguintes rendimentos: em uma propriedade com 200 suínos em terminação é possível produzir $16 \mathrm{~m}^{3}$ de biogás, $6 \mathrm{~kg}$ de GLP ou gerar $16 \mathrm{kWh}$ de energia elétrica por dia (BGS, s.d.). O Brasil como um todo possui 1.600.000 matrizes tecnificadas de onde seria possível produzir $115.200 \mathrm{~m}^{3} /$ dia de biogás no país conforme estimativa de Pazinato Dias et alii (2016).

Para o rebanho suinícola catarinense para o ano de 2008 foi estimada uma produção de 556 milhões de $\mathrm{m}^{3}$ biogás /ano e 309 milhões de $\mathrm{m}^{3} \mathrm{CH} 4 /$ ano (DAL MAGO, 2009). Angonese et alii (2006), analisando a eficiência energética de um sistema de produção de suínos com biodigestor, verificaram que o biofertilizante representa $30,2 \%$ e o biogás $13 \%$ dos valores totais da energia do sistema. O suíno representa 56,8\%. A energia "recuperada" do biogás e do biofertilizante quase chegam a 50\% do sistema total. Esses dados estão alinhados com os valores encontrados por Goldemberg (1998) e Beber (1989). A efetiva utilização destes dois "sub-produtos" seria a renovação de energia, reduzindo o impacto ambiental e minimizando a importação de energia segundo os autores.

A Resolução Normativa 482 da Agência Nacional de Energia Elétrica - ANEEL, de abril de 2012, estabelece a possibilidade de comercialização da energia gerada pelo sistema de biogás. Porém, Martins e Oliveira (2011) apud Pazinato Dias et alii (2016, p.2) "relatam ser mais vantajoso economicamente o uso desta energia na propriedade rural, substituindo ou reduzindo a aquisição da energia elétrica distribuída pela concessionária”. Em Santa Catarina, apenas recentemente a Celesc passou a adquirir energia produzida com biogás da granja São Roque em junho de 2010.

\section{EXPERIÊNCIAS CATARINENSES COM BIODIGESTORES}

Esta seção descreve experiências públicas e privadas recentes na utilização de biodigestores na atividade da suinocultura em Santa Catarina ${ }^{19}$. A maioria das experiências na última década foi com o Modelo Contínuo Canadense ${ }^{20}$.

\footnotetext{
${ }^{19}$ A pesquisa não exaure todas as experiências com biodigestores a partir dos anos 2000 em Santa Catarina.

${ }^{20} \mathrm{O}$ biodigestor Modelo Contínuo Canadense é um modelo que o fluxo de entrada e saída de resíduos é constante, diferente do modelo de Batelada. São três tipos de fluxo contínuo: Chinês, Canadense e Indiano. Ver: https://emasjr.com.br/2018/04/22/tipos-biodigestor/
} 


\subsection{EXPERIÊNCIA DA SADIA/BRF}

A Sadia, atual BRF, iniciou em 2003 ações que culminaram com a criação do Programa 3S (Sistema de Suinocultura Sustentável) ${ }^{21}$. Os primeiros estudos e projetos foram relacionados à mitigação de gases do efeito estufa via construção de biodigestores. Em 2004 foi oficializado o programa e instalados os primeiros biodigestores. O sistema permite a queima dos gases gerados no processo do tratamento dos dejetos. Ainda em 2004, a Sadia criou o Instituto Sadia para promover o desenvolvimento sustentável em parceria com a comunidade $^{22}$ (MARCOVITCH, 2008).

De adesão voluntária o $3 \mathrm{~S}$ pretendia, ao gerenciar os resíduos, reduzir a emissão de GEE gerando assim melhores condições de vida dos produtores de suínos, com um ambiente de trabalho mais saudável (MARCOVITCH ${ }^{23}$, 2008). A modificação de qualidade ambiental é importante, pois, “(...) a suinocultura no Brasil não é sustentável devido aos níveis de poluição ambiental severa que causa precárias condições de trabalho e de vida de seus produtores" (MARCOVITCH, 2008, p.27). O tratamento de efluentes e resíduos fazia parte de um conjunto amplo de ações para a sustentabilidade desenvolvida pela sadia/BRF.

“Em 2006, a empresa teve o Programa 3S reconhecido pelo Prêmio Brasil Ambiental, na categoria Mecanismo de Desenvolvimento Limpo (MDL), (...) como projeto importante dentro de critérios de desenvolvimento sustentável" (MARCOVITCH, 2008, p.12). Dos 3.500 suinocultores integrados na época, apenas 1.130 possuíam biodigestores implantados em 2006/2007. Não foi possível maior alcance, na implantação, junto aos pequenos produtores por que uma nova metodologia de medição de emissão de carbono tornou mais cara a mesma $^{24}$ (MARCOVITCH, 2008).

O Programa 3S da Sadia rendeu a sua inclusão no Relatório de 2008 da ONU sobre desenvolvimento $^{25}$. O Relatório considerou o Programa 3S importante, pois a empresa incluiu a sustentabilidade no seu Plano de renda dos produtores uma vez que o processo de coleta e tratamento dos efluentes, em especial os gases de efeito estufa, poderiam ser comercializados

\footnotetext{
${ }^{21}$ Uma descrição mais detalhada do processo de instalação do Programa $3 \mathrm{~S}$ da Sadia (atual BRF) e das modificações necessárias podem ser encontradas em Marcovitch (2008) e também no livro do mesmo autor "Para mudar o futuro" - Edusp/saraiva, 2006.

22 Os objetivos específicos desta parceria com a comunidade são: desenvolver projetos de preservação de recursos naturais; fomentar a pesquisa tecnológica e a educação ambiental; viabilizar o Programa $3 \mathrm{~S}$ através de busca de fontes de financiamento e venda dos créditos de carbono, com repasse dos resultados financeiros aos integrados; e promover a Educação Ambiental, responsabilidade social e acesso às novas tecnologias (MARCOVITCH, 2008, p.27).

23 As análises e conclusões de MARCOVITCH (2008) utilizaram como fontes de pesquisa informações impressas encaminhadas pela empresa e materiais institucionais do Programa 3S (informativo interno - mar/abr 2007 e nov./dez. 2006 - ano 1, no. 1 e 2 e entrevista com Meire Ferreira (Sadia/SP).

${ }^{24}$ A nova metodologia teria elevado muito os custos inviabilizando a disseminação no uso dos biodigestores.

${ }^{25}$ O Relatório tem o título "Criando Valores para Todos: Estratégias de Negócios com os Pobres".
} 
dentro do Mecanismo de Desenvolvimento Limpo (créditos de carbono) facilitando os investimentos nos biodigestores (AGROSOFT, 2008, s.p). Realmente, até 2008 a Sadia já havia negociado créditos junto ao European Carbon Found que somaram mais de 2,4 milhões de toneladas de $\mathrm{CO} 2$. Tais créditos teriam contrapagamentos durante dez anos, quando comprovada a captura do gás nos biodigestores (MARCOVITCH, 2008). Aparentemente estes pagamentos não chegaram a se concretizar.

Vale destacar que o último relatório de atividades da BRF disponível no momento da execução desta pesquisa (Relatório 2015) só menciona a preocupação da empresa com o gerenciamento dos efluentes, mas não detalha ações específicas com o uso de biodigestores nas propriedades rurais. Procurada para se manifestar a respeito a empresa não retornou contato para verificação da evolução do programa. Alguns entrevistados apontam para abandono dos biodigestores pelos produtores.

\subsection{OUTRAS EXPERIÊNCIAS DE BIOGÁS EM SANTA CATARINA}

A Cooperativa Central Aurora Alimentos - possui desde 2007, em duas granjas em Chapecó equipamento de biodigestão (figura 2) para tratar os efluentes e gerar energia com o biogás. O processo produz 20 mil quilos de gás por mês originado dos resíduos de 5.000 suínos e alcança 70\% do consumo energético da unidade frigorífica (DEBONA, 2013).

A Cooperativa Agroindustrial Alfa - Cooperalfa instalou em sua Unidade de Produção de Leitões (UPL) do município de Palma Sola três biodigestores que produzem energia para atender $100 \%$ das necessidades da granja, sendo, portanto, autossustentável segundo Clenoir Antônio Soares engenheiro agrônomo da Cooperalfa (PROJETO, s.d.) ${ }^{26}$.

\footnotetext{
${ }^{26}$ Ver mais em SOARES, Clenoir Antônio. Estudo da produção de biogás em escala real a partir de dejetos suínos. Dissertação Mestrado em Ciência e Tecnologia Ambiental. Universidade Federal da Fronteira Sul. Erechim/RS. 2016.
} 
Figura 2 - Biodigestores: grandes lonas infladas com o biogás (Aurora)

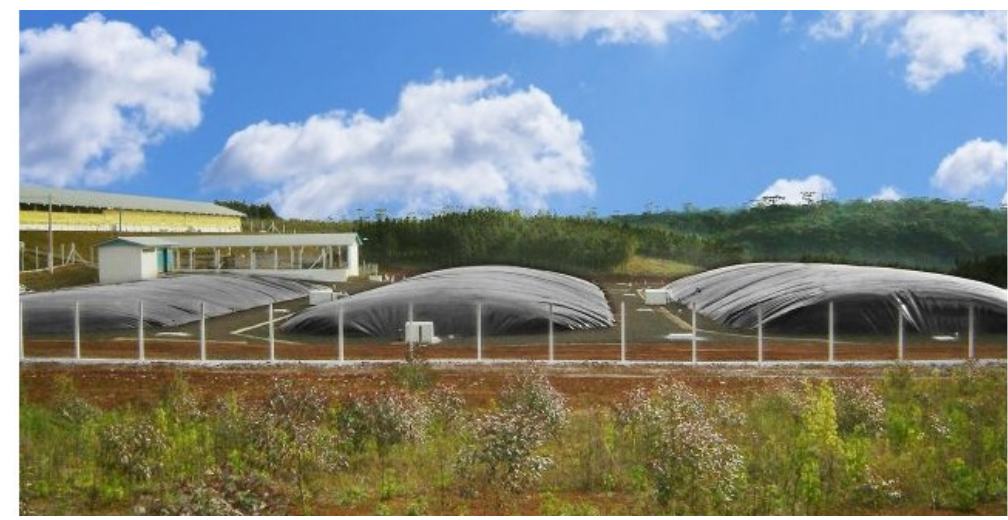

Fonte: Gter Energias Renováveis.

A Eletrosul fomentou o uso de biodigestores por meio do Projeto Alto Uruguai, cuja primeira fase implantou 35 biodigestores em localidades de Santa Catarina e Rio Grande do Sul (29 cidades). A segunda etapa ocorreu em Itapiranga e visava, sobretudo a queima de metano para geração de energia, com investimento de $\mathrm{R} \$ 10$ milhões em 10 biodigestores em várias propriedades do Município (DUDEK, 2013). A Eletrosul não disponibilizou informações para avaliação do andamento dos projetos citados durante a execução desta pesquisa,

Outros exemplos, em Santa Catarina, no município de Iomerê, a Master Iomerê e Granja Comelli implantara sistemas de geração de biogás a partir de dejetos ${ }^{27}$. Porém, os técnicos afirmam que por questões de ordem tecnológica, climática e de baixa eficiência técnica e econômica, a geração de biogás sofreu descontinuidade e se encontram desativadas ou redimensionados. Estes problemas também ocorreram em Videira na Granja São Roque II (figura 3).

\footnotetext{
${ }^{27}$ A Master Iomerê é uma granja que trabalha com 1950 matrizes e responde pela disponibilização de leitões desmamados (54000 suínos/ano) para diferentes integrados terminadores da BRF e da Master Agropecuária (MASTER, 2017).
} 
Figura 3 - Biodigestor da São Roque II desativação/fatores climáticos e

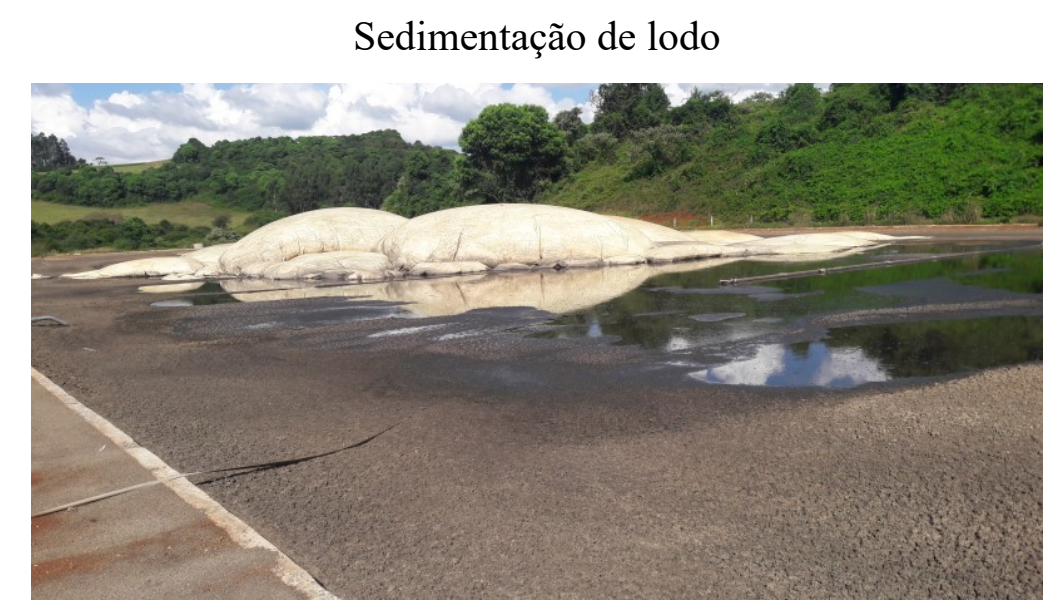

Fonte: Autores em 10 mar. 2017.

A Master Iomerê foi a pioneira em termos de aplicação da tecnologia de biogás na região. Para tal, participou de uma rede de atores ${ }^{28}$ no Projeto de Validação de Tecnologias para o Manejo, Tratamento e Valorização dos Dejetos de Suínos em Santa Catarina que ocorreu de 2003/2007 via Fundo Verde Amarelo ${ }^{29}$. Recebeu aporte de recursos a fundo perdido para custear parte da infraestrutura das instalações do sistema de tratamento ${ }^{30}$.

Todavia, a tecnologia aplicada não demonstrou viabilidade. Diferentes testes realizados pela rede de atores que compunham o referido projeto não validaram a tecnologia utilizada referente à geração de biogás ${ }^{31}$. Dificuldades associadas à concepção do formato do biodigestor implantado na unidade piloto da Master que não atendia ao porte e fluxo de efluentes e a variabilidade de fatores climáticos como a temperatura ${ }^{32}$. Além disso, fatores qualitativos dos efluentes variáveis em função do manejo da produção e utilização de produtos diversos impactavam no processo de geração de gás. Também a carga de efluentes interferia com a estabilidade do sistema de produção do gás. Tudo acabou impactando nos rendimentos e manejo da unidade. Ainda dificuldades dos atores do Projeto em continuarem

\footnotetext{
${ }^{28}$ Os atores foram: Financiadora de Estudos e Projetos (FINEPE), Embrapa Suínos e Aves, EPAGRI, UNOESC, UFSC, Empresa Perdigão Agroindustrial (atual BRF), Fundo de Apoio ao Desenvolvimento Rural Sustentável do Estado de Santa Catarina por meio da Fundação de Amparo à Pesquisa e Inovação do Estado de Santa Catarina (Funcitec atual FAPESC).

${ }^{29}$ O Fundo Verde Amarelo é um dos fundos setoriais de Ciência e Tecnologia que é voltado para interação universidade-empresa, é um dos fundos classificados como transversal, a exemplo do fundo de melhoria da infraestrutura de ICTs (Infraestrutura). Os 14 demais fundos são os específicos (FINEP, 2017).

${ }^{30}$ Foram aproximadamente $\mathrm{R} \$ 500.000,00$ mil reais para equipamentos e instalações para o sistema.

${ }^{31}$ A rede de atores era composta por: Laboratório de Análise de Efluentes da Unoesc Videira, Embrapa Suínos e Aves e Departamento de Engenharia Sanitária e Ambiental da UFSC.

${ }^{32}$ Parâmetro incontrolável, mas de grande importância para o bom funcionamento e estabilização. A temperatura e radiação solar influem na velocidade da fotossíntese (predomínio entre as espécies de algas e consequente oxigênio produzido) e no metabolismo das bactérias responsáveis pela degradação dos dejetos de suínos. Ainda, a atividade biológica decresce à medida que cai a temperatura - uma queda de $10^{\circ} \mathrm{C}$ na temperatura reduzirá a atividade microbiológica pela metade e na região sul dos pais, muitas vezes tem três climas no mesmo dia.
} 
atuando em rede (termino dos recursos) e manutenção da equipe técnica (disponibilidade de recursos suplementares) das empresas privadas em dispor de técnicos para operar e continuarem os testes de eficiência, a geração de gás foi desativada. A empresa voltou a utilizar as formas convencionais de tratamento de dejetos.

A segunda empresa a adotar sistemas de geração de biogás no município de Iomerê foi a Granja Comelli ${ }^{33}$ que instalou, em 2004, com recursos próprios, coberturas de lonas em tanques que já eram utilizados para dejetos de suínos. Segundo o entrevistado Lauermann $(2017)^{34}$ a produção de biogás era apenas para queima e o sistema não chegou a funcionar de maneira constante e após a finalização do processo a experiência foi abandonada. A dificuldade de dimensionamento de gás e a tecnologia empregada nas lonas de cobertura determinou a inviabilização do processo. As lonas acabaram estourando e a empresa responsável pela instalação não mais atua na atividade e, portanto, não há assistência e as lonas estão inservíveis.

Outro exemplo, no município de Videira foi o projeto de geração de biogás de 2003, o Projeto Granja São Roque de Redução de Emissão de GEE com biodigestores anaeróbios para captar o gás metano, gerar energia elétrica e auxiliar na sustentabilidade da unidade. Somente em 2008 passou a operar com geração de biogás e energia. O entrevistado Rogoski (2017) afirma que o Projeto buscava a melhoria da qualidade de vida da população, diminuindo a incidência de vetores patogênicos, o odor e melhorando a qualidade do efluente tratado.

Em 2011 o Grupo Master Videira adquiriu a Granja São Roque e estabeleceu parceira com as Centrais Elétricas de Santa Catarina (Celesc) para comercialização de energia elétrica excedente. Segundo Gregolin (2012) o sistema da Granja São Roque proporcionou redução de até $20 \%$ dos custos de energia utilizados na propriedade em 2012. Em 2016 as lagoas anaeróbicas instaladas no projeto foram desativadas em razão de tempestade que rompeu as coberturas e ao assoreamento das mesmas com lodo.

De acordo com o entrevistado Gregolin (2017) o formato de operação dos biodigestores se apresentou como uma dificuldade, pois fatores como temperatura da região interferem no aquecimento dos biodigestores e na produção de biogás. Afirma que a agitação e o escoamento do lodo e sedimentado das lagoas anaeróbicas é um problema a ser resolvido. Pondera que estas e outras dificuldades provocaram colapso do sistema e por isso foi desativado. Destaca, ainda, que o processo de purificação do biogás produzido é fator restritivo no sistema do Projeto, pois a presença de compostos químicos (enxofre) reduz a

\footnotetext{
${ }^{33}$ Atua como uma integradora na produção de 60.000 leitões ano e possui 2.200 matrizes.

${ }^{34}$ Entrevista concedida aos pesquisadores, referenciada no final do artigo.
} 
vida útil dos equipamentos. Conclui que o sistema de geração no formato atual está comprometido pela baixa eficiência em termos técnicos e econômicos (GREGOLIN 2017).

Porém, o Projeto Granja São Roque está sendo redimensionado dentro de um formato de parcerias de diferentes atores (iniciativa privada, governo, agências de fomento, universidades e instituições de pesquisa), em novo projeto de tratamento de dejetos que já conta com investimento de 2 milhões de reais (GREGOLIN, 2017).

As linhas de financiamento via Programa ABC cujas taxas de juros variam entre 8\% a 8,5\% ao ano e com prazo de 10 anos e mesmo o Inova Agro da FINEP seriam impraticáveis aos suinocultores dadas as expectativas de receitas menores e variáveis em razão dos ciclos de receitas e custos decorrentes de imprevisibilidade climática e de mercado que acabam afetando a receita dos negócios conforme analisam Lauermann (2017), Rogóski (2017) e Gregolin (2017).

\subsection{A SITUAÇÃO DO BIOGÁS NAS MICRORREGIÕES}

\subsubsection{Concórdia}

Técnicos de extensão pública e privada da região de Concórdia explanaram sobre a dificuldade da manutenção de biodigestores e que isso não tem estimulado os produtores a investirem nesse método de tratamento de efluentes. Há problema de assoreamento do fundo do depósito do biodigestor o que exige retirada manual, a própria lona que recobre o biodigestor precisa de manutenção, os equipamentos de queimar o biogás também exigem manutenção. Tudo isso exige volume razoável de recursos para uma atividade cíclica e de baixa margem como a suinocultura. Além de tudo, não existe política de estímulo via crédito e mesmo assistência técnica para facilitar a disseminação da prática do uso de biodigestores. A maioria dos produtores ainda está preferindo tratamento por lagoa de contenção e fermentação que podem atingir até 120 dias. Os extensionistas de cooperativas e da EPAGRI orientam os produtores nos casos de eventuais reduções de criações e substituição por outra atividade quando ocorre por exemplo a saturação de uma bacia hidrográfica por excesso de produção o que provoca grande volume de resíduos. Praticamente todos os associados da cooperativa local (600 produtores) não utilizam biodigestores, apenas 1 ou dois o fazem. Entre cooperados até 10 produtores utilizam a prática da composteira que é o tratamento com leiras de serragem misturada ao esterco e que passam por compostagem e necessitam de revolvimento mecânico. O não recebimento de pagamentos ou créditos por parte de quem fez utilização de biodigestores tem levado até mesmo os produtores do programa de biodigestores 
de agroindústria local a retraírem a utilização da prática, com equipamentos abandonados na região.

Isso foi confirmado por outro técnico que atua em Concórdia ao salientar que aparentemente o projeto de biodigestores na região estaria em câmara lenta e o mais comum são dois tipos de tratamento de dejetos a bioesterqueira que fermenta o material durante 3 meses para posterior distribuição em área de lavoura e a composteira que o material vai acumulando com maravalha por até um ano quando estará completamente neutralizado e pronto para uso como fertilizante.

\subsubsection{Xanxerê}

Verificou-se que na região de Xanxerê ocorreu redução do número de produtores dedicados à suinocultura. As entrevistas com técnicos apontaram que haverá continuidade na redução do número de produtores no futuro. Os elementos que pressionam para a redução da atividade são: i) o problema de dificuldade de mão de obra para fazer o manejo da criação (somente restaram nas propriedades pequenas o casal e que ao avançarem em idade acabam cansando da atividade), este caso ocorre sobretudo a produtores que possuem até 300 animais; ii) a remuneração da atividade é cíclica com períodos de melhora e de piora principalmente relacionada ao problema de preço pago pelas agroindústrias que acabam remunerando em razão das flutuações do mercado, em termos de conversão de carcaça e mesmo época do ano e, o problema do custo de produção que tem variado em razão de oferta de matéria prima, predominantemente o milho; iii) a crescente pressão da legislação ambiental que não concede o licenciamento se os produtores não cumprirem com exigências cada vez mais crescentes. Os produtores mais impactados seriam aqueles com produção de 300 a 1500 animais. Por exemplo, atualmente há exigência de cisterna nas propriedades de criadores de suínos para coletar a água da chuva para evitar a coleta de água de córregos dado os problemas recorrentes de estiagens. O técnico explicou que há apoio para a construção/instalação de cisternas se o produtor for enquadrável no Pronaf mais alimentos no qual ele pagará juros de $2,5 \%$ ao ano, caso contrário estará sujeito a taxas maiores do que $8 \%$. Informou ainda que a maioria dos produtores não utiliza biodigestores, fazendo, portanto, o tratamento dos dejetos de forma convencional (esterqueira, lagoa de decantação ou outro). Apenas 2 ou 3 produtores de médio porte, que criam/engordam ao redor de 1.500 suínos, possuem biodigestores, mas não fazem a queima do biogás. Na região atua a empresa de energia elétrica Iguaçu Energia e não utiliza nenhum esquema de permuta com a energia gerada por queima de biogás, 
diferentemente da $\operatorname{Celesc}^{35}$. Apenas um produtor na região com rebanho de 4.000 suínos faz tratamento por compostagem. Este produtor voltou a utilizar o processo de esterqueira, por dificuldade de continuar a operar o sistema de revolvimento do material compostado, talvez em razão de falta de supervisão de quem vendeu o equipamento ao produtor. É um equipamento caro e que poderá ser abandonado pelo produtor pelas dificuldades apontadas. Voltando à questão do impacto da legislação ambiental cada vez mais restritiva foi apontado o caso da Bacia do Rio Vitinho que seria rio classe $\mathrm{I}^{36}$. Nesta bacia muitos produtores assinaram há alguns anos Termos de Ajuste de Conduta que os obrigava a fazerem muitas modificações em suas criações e isto não foi possível de forma que entre 10 a 12 produtores tiveram que abandonar a atividade, não restou ninguém produzindo suínos lá.

\subsubsection{Joaçaba, Iomerê e Videira}

São municípios de uma mesma microrregião, de Joaçaba ${ }^{37}$. O entrevistado, técnico da Epagri de Joaçaba informou que houve retrocesso nas experiências de biodigestores na região de Joaçaba, pois, com a entrada de energia elétrica nas propriedades reduziu a necessidade de fontes alternativas para aquecimento dos leitões ou outra finalidade. Além disso, se há alguns anos havia suinocultura na maioria das propriedades, atualmente $80 \%$ delas se dedicam a pecuária leiteira. Sendo assim, reduziu a pressão disseminada de tratamento de dejetos de suínos para a maioria das propriedades. O mínimo que existe de biodigestores é apenas para queima do biogás e não para o aproveitamento energético. Existem inclusive campânulas de biodigestores sem uso, abandonadas, na região. As experiências de Iomerê (Master Iomerê e Granja Comelli) e Videira (Granja São Roque) não parecem apontar bons resultados conforme se viu no tópico 5.2 .

\section{CONSIDERAÇÕES FINAIS}

Observou-se, na pesquisa em 2017, a baixíssima utilização de biodigestores nas microrregiões analisadas. O acervo técnico sobre tratamento de dejetos é grande e em especial aqueles compilados e pesquisados pela EMBRAPA. As diversas experiências a campo com biodigestores do Modelo Contínuo Canadense parecem apontar para algumas dificuldades conforme argumentaram os entrevistados das regiões de Joaçaba, Concórdia e Xanxerê. Esta situação tem levado ao abandono do tratamento com biodigestores. A tendência é a exclusão

\footnotetext{
${ }^{35}$ Haveria um esquema de aquisição de energia gerada com a queima de biodigestores com a CELESC que permitiria aos produtores compensarem os valores "vendidos" de energia pelo produtor de suínos em outras propriedades/residências do produtor. Não seria uma compra real, mas uma compensação.

${ }^{36}$ Rio que possui coleta de água para abastecimento urbano segundo entrevistado.

${ }^{37}$ São 27 municípios nesta microrregião.
} 
dos produtores que não conseguirem cumprir as exigências legais, conforme se verificou em Xanxerê, além da óbvia pressão oriunda de preços e custos. Aparentemente os estímulos que esparsamente existem não estão conseguindo convencer os produtores a migrarem das lagoas/esterqueiras para tratamentos com biodigestores, até por que em várias regiões não há previsão de negociar a energia com as companhias de eletricidade locais. Além disso, pesam ao produtor as dificuldades operacionais para lidarem com a necessidade de manutenção de equipamentos e de retirada de lodo do fundo dos depósitos. Haveria mesmo um retrocesso nas experiências da Sadia/BRF, conforme apontaram alguns entrevistados.

Por último, se a sociedade deseja maior adoção da prática da produção e queima do biogás deverá estimular via apoio financeiro e de tecnologia que facilite o manejo e manutenção do sistema, caso contrário somente coercitivamente o produtor adotará uma prática mais trabalhosa (biodigestores) que as bioesterqueiras atualmente empregadas.

\section{REFERÊNCIAS}

ABREU, F. V.; AVELINO, M. Análise energética da eficiência do motor de combustão interna utilizando como combustível o biogás. Anais... VII CONEM - Congresso Nacional de Engenharia Mecânica, São Luís - MA, Brasil, 8p, 2012.

ACCS. Relatório Anual 2011. Associação Catarinense de Criadores de Suínos. (Disponível em http://www.accs.org.br/arquivos_internos/index.php?abrir=relatorios_anuais, acessado em 20 fev. 2017).

BGS. Blog BGS Equipamentos. Cálculo para produção de biogás. (Disponível em http://bgsequipamentos.com.br/blog/calculo-de-producao-de-biogas-2/, acesso em 09 fev. 2017).

AGROSOFT. Sadia é incluída em relatório da ONU sobre desenvolvimento. Blog Agrosoft Brasil: agronegócio sustentável, 2008. (Disponível em http://www.agrosoft.org.br/br/sadia-eincluida-em-relatorio-da-onu-sobre-desenvolvimento/economia, acessado em 24 fev. 2017).

AMARAL, Armando Lopes do; et ali. Boas Práticas de Produção de Suínos. Concórdia, EMBRAPA suínos e aves, dez. /2006. (Disponível em https://www.embrapa.br/suinos-e- 
aves/busca-de-publicacoes/-/publicacao/443977/boas-praticas-de-producao-de-suinos, acessado em 20 fev. 2017). (Circular técnica, 50)

ANGONESE, André R. et alii. "Eficiência energética de sistema de produção de suínos com tratamento dos resíduos em biodigestor". Revista Brasileira de Engenharia Agrícola e Ambiental, Campina Grande, PB, DEAg/UFCG, v.10, n.3, p.745-750, 2006.

BEBER, J. A. C. Eficiência energética e processos de produção em pequenas propriedades rurais. Santa Maria; UFSM, 1989, 295p. Dissertação Mestrado

BIODIGESTOR Anaeróbio (11 jan. 2016) (Disponível em: http://www.portaldobiogas.com/biodigestor-anaerobio/, acessado em 10 fev. 2017).

BIONDO, Mauro Mauricio. Biodigestor: Uma energia renovável pouco utilizada em SC. Chapecó. UNOCHAPECÓ/Jornalismo/Jornalismo ambiental, 3 ${ }^{\text {a }}$. fase. 1 jul. 2015.

BRASIL. LEI $\mathrm{N}^{\mathrm{o}}$ 6.938, de 31 de agosto de 1981. Disponível em http://www.planalto.gov.br/ccivil 03/LEIS/L6938.htm, acesso em 15 de setembro de 2016.

BRASIL. Ministério da Ciência, Tecnologia e Inovação. Estimativas anuais de emissão de gases de efeito estufa no Brasil. Brasília: MCTI, 2014. 164 p.

BRASIL. SENADO FEDERAL DO BRASIL. Conferência Rio-92 sobre o meio ambiente do planeta: desenvolvimento sustentável dos países. Disponível em http://www.senado.gov.br/noticias/Jornal/emdiscussao/rio20/a-rio20/conferencia-rio-92sobre-o-meio-ambiente-do-planeta-desenvolvimento-sustentavel-dos-paises.aspx, $\quad$ acessado em 30 de mar. 2016.

BRF. Relatório Anual 2015. (Disponível em https://www.brfglobal.com/brasil/responsabilidade-corporativa/relatorio-anual, acesso em 22 fev. 2017).

BGS. Quanto de biogás eu posso produzir? S.D. (Disponível em https://www.bgsequipamentos.com.br/calculo-da-producao-de-biogas/, acessado em 26 mar. de 2016). 
COMEX DO BRASIL/ABPA. Exportações de carne suína crescem 32\% em 2016 e geram receita de US\$ 1,483 bilhão. 17 jan. 2017. Disponível em: http://www.comexdobrasil.com/exportacoes-de-carne-suina-crescem-32-em-2016-e-geramreceita-de-us-1483-bilhao/, acessado 21 fev. 2017

DAL MAGO, Anigeli. Avaliação de biodigestores com o uso de dejetos de suínos, em braço do norte e em concórdia. Florianópolis; UFSC - Programa de Pós-Graduação em Engenharia Ambiental. Dissertação de Mestrado, 2009.

DEBONA, Darci. Aurora, de Chapecó, transforma os dejetos dos suínos em biogás. Diário Catarinense. Florianópolis, 13/08/2013.

DIESEL, Roberto; MIRANDA, C.R.; PERDOMO, C.C. "Coletânea de tecnologias sobre dejetos de suínos". Boletim informativo BIPERS Pesquisa \&Extensão. v.10, n.14, 2002. Disponível em https://docsagencia.cnptia.embrapa.br/suino/bipers/bipers14.pdf, acessado em 13 jan. 2017.

DUDEK, Patricia Mazzioni “Apesar de ser uma alternativa para a produção de energia limpa, o alto custo de implantação do sistema inviabiliza a produção de Biogás”. Unochapecó, Chapecó, 2013. Disponível em https://www.unochapeco.edu.br/static/files/premiojornalismo-ambiental/biodigestores.pdf. . Acesso em 2 mar. 2017.

FATMA. Instrução Normativa No 11 - Suinocultura. Florianópolis, 2014. Disponível em http://www.fatma.sc.gov.br/ckfinder/userfiles/arquivos/ins/11/IN\%2011\%20Suinocultura.doc Acesso em 01 set. 2016.

GERBER, P. J. et al. Tackling climate change through livestock: a global assessment of emissions and mitigation opportunities. Rome: FAO, 2013.

GIEHL, Alexandre Luís. Carne Suína. Síntese Anual da Agricultura de Santa Catarina 2015/2016. EPAGRI/CEPA. Florianópolis, 2016.

GOLDEMBERG, J. Energia, meio ambiente \& desenvolvimento. São Paulo: Editora da USP, 1998. 
GREGOLIN, Cleonei. Entrevista sobre Dificuldades/facilidades do sistema de biogás da Granja São Roque - Master S. Roque. Videira, 10 mar. 2017.

GRIEBELER, Jaques. A exclusão agropecuária no Oeste Catarinense: o caso da suinocultura no período de 1994/2001. UFSC/Departamento de Economia. Monografia Economia. Florianópolis, 2002.

GUESSER, Filipe. Exigências ambientais na suinocultura e levantamento da percepção dos suinocultores de Ibicaré/SC. UFSC/Departamento de Economia. Monografia. Florianópolis, 2016.

HENN, A. A avaliação de dois sistemas de manejo de dejetos em uma pequena propriedade produtora de suínos: condição de partida. 157 f. Dissertação (Mestrado em Engenharia Ambiental) - UFSC, Florianópolis, 2016

IBGE. Pesquisa Pecuária Municipal 2016

IBGE. Censo agropecuário 2006: Brasil, grandes regiões e unidades da federação: segunda apuração. Rio de Janeiro, 2012. Disponível em: http://servicodados.ibge.gov.br/Download/Download.ashx?http=1\&u=biblioteca.ibge.gov.br/ visualizacao/livros/liv61914.pdf. Acesso em 27 de set. 2016.

IBGE. Censo Demográfico 2010. Disponível em http://www.sidra.ibge.gov.br, acessado em 12 out. 2016.

IBGE. Produção da Pecuária Municipal 2015. Disponível em http://www.sidra.ibge.gov.br. Acesso em 15 nov. 2016.

KRUGER, Silvana; et alii. "Práticas organizacionais da atividade suinícola na região Oeste de Santa Catarina- Brasil". Book of abstracts: XI Iberian Conference on Rural Studies. Vila Real/Portugal 13 a 15 de out. 2016. Disponível em http://xicier2016.utad.pt/sites/all/themes/professional responsive theme/images/files/Book_A bstracts.pdf. Acesso 18 fev. 2017. 
LAUERMANN, Rudinei. Entrevista sobre Sistema de Biogás na Empresa Comelli de Iomerê. Iomerê, 12 mar. 2017.

MACHADO, Jurandir Soares. Suínos. Síntese anual da agricultura de Santa Catarina 98/99. Instituto CEPA/SC. Florianópolis, 1999.

MAIA, Alexandre Gori; ROMEIRO, A. R.; JUSTO, M. C. D. de M. Custo-efetividade de tratamentos de dejetos de suínos no Oeste Catarinense. In: TÔSTO, S.G. et alii. Valoração de serviços ecossistêmicos: metodologia e estudos de caso. EMBRAPA/ Brasília: Embrapa Monitoramento por Satélite, 2015.

MINISTÉRIO DA AGRICULTURA, PECUÁRIA E ABASTECIMENTO. O Aquecimento Global e a Agricultura de Baixa Emissão de Carbono. Brasília MAPA / EMBRAPA / FEBRAPDP, 2011.

MAPA prioriza suinocultura no Plano ABC. Ministério da Agricultura, Pecuária e Abastecimento/Suinocultura ABC. Brasília 21 dez. 2016. (Disponível em http://www.agricultura.gov.br/assuntos/sustentabilidade/plano-abc/suinocultura-abc/arquivosboletim-informativo/1-mapa-prioriza-suinocultura-no-plano-abc.pdf/view. Acesso em 21 fev.2017).

MARCOVITCH, Jacques. Projetos sustentáveis de oito empresas brasileiras: um survey com inovadores - primeira avaliação - 2008 - Disponível em: http://www.usp.br/mudarfuturo/cms/wp-content/uploads/290808MClimaEstrEmpr.pdf Acesso em 24 fev. 2017.

MASTER. Unidades Produtivas. Videira, 2017. Disponível em: http://master.agr.br/estruturasolida/. Acesso em 13 mar. 2017.

OLIVEIRA, P.A. Produção e aproveitamento do biogás. Concórdia, EMBRAPA, 2004.

OLIVEIRA, P.A.V.; HIGARASHI, M.M. Geração e utilização de biogás em unidades de produção de suínos. Concórdia, EMBRAPA Suínos e Aves. jun./2006. Disponível em: 
http://www.cnpsa.embrapa.br/sgc/sgc publicacoes/publicacao 14177t4r.PDF Acesso em 05 mar. 2017.

PAZINATO DIAS, Cleandro et alii. A suinocultura brasileira e seu potencial de geração de energia elétrica através do tratamento dos dejetos suínos. Congresso da Sociedade Brasileira de Economia, Administração e Sociologia Rural (SOBER). 54º . Anais... Maceió, ago./2016

PROJETO Suinocultura de Baixa Emissão de Carbono conhece a Cooperalfa, a Granja Palma Sola e o Sistema Aurora. Boletim informativo, n. 07, s.1., s.d. Disponível em: http://www.agricultura.gov.br/assuntos/sustentabilidade/plano-abc/suinocultura-abc/arquivosboletim-informativo/7-projeto-conhece-a-cooperalfa-a-granja-palma-sola-e-o-sistemaaurora.pdf. Acesso em 26 fev. 2017.

RODRIGUES, A.T.; GELINSKI NETO, F; CARVALHO JÚNIOR, L. C.; O comportamento da relação de troca na suinocultura catarinense no período de 2000 a 2012 In: $51^{\circ}$ Congresso SOBER. Anais... Belém - PA. UFPA, jul./ 2013.

ROGOSKI, Nédio Ricardo. Entrevista sobre Sistemas de tratamento de efluentes na suinocultura. Tangará, 07 mar. 2017.

SANTOS FILHO, Jonas Irineu dos; et alii. Cenários e oportunidades para a produção familiar de suínos: o que há de novo e o que já é possível. . Concórdia/SC, EMBRAPA suínos e aves, Documentos 174, Outubro, 2015. Disponível em: https://www.embrapa.br/suinos-eaves/busca-de-publicacoes/-/publicacao/1030927/cenarios-e-oportunidades-para-a-producaofamiliar-de-suinos-o-que-ha-de-novo-e-o-que-ja-e-possivel. Acesso em 20 fev. 2017.

SAVIOTTI, Bruno et alii. Suinocultura de baixa emissão de carbono: tecnologias de produção mais limpa e aproveitamento econômico dos resíduos da produção de suínos. Ministério da Agricultura Pecuária e Abastecimento/IICA/EMBRAPA. Brasília. 2016. Disponível em: http://www.iicabr.iica.org.br/wp-content/uploads/2016/01/Suinocultura-debaixa-emiss\%C3\%A3o-de-carbono-cartilha-MAPA-IICA-Brasil.pdf. Acesso em 07 mar. 2017. 
TESTA, Vilson Marcos, et alii. O Desenvolvimento Sustentável do Oeste Catarinense (proposta para discussão). EPAGRI/CPPP. Florianópolis, 1996.

TORESAN, Luiz. Desempenho da agropecuária catarinense - 2016. In: Síntese Anual da Agricultura de Santa Catarina 2015/2016. EPAGRI/CEPA. Florianópolis, 2016.

TORRES, Tainara Regina Cerutti; SILVA, Robson Leal da. Potencial do biogás proveniente da suinocultura para a geração de energia elétrica no estado de mato grosso do sul. In: AGRENER GD 2015 - $10^{\circ}$ Congresso sobre Geração Distribuída e Energia no Meio Rural. Anais... São Paulo, USP, 11 a 13 de novembro de 2015.

WANDER, Alcido Eleonor et alii. "Uma avaliação formativa do Plano ABC". Revista de Política Agrícola/MAPA/CONAB. Brasília, n.3, jul./ago./set. 2016, p. 62-72.

WEYDMANN, Celso Leonardo. Suinocultura e Meio ambiente: Evidências dos EUA. Sociedade Brasileira de Economia, Administração e Sociologia Rural. Disponível em: http://www.sober.org.br/palestra/12/080406.pdf., acesso em 24 d abril de 2016. 